\title{
The case of a patient with MIRAGE syndrome with familial dysautonomia-like symptoms
}

\author{
Yuki Kawashima-Sonoyama ${ }^{1,2}{ }^{凶}$, Keisuke Okuno ${ }^{1}$, Tomotsune Dohmoto ${ }^{3}$, Kanako Tanase-Nakao ${ }^{4}$, Satoshi Narumi ${ }^{4}$ and \\ Noriyuki Namba ${ }^{1}$
}

(c) The Author(s) 2021

We describe a case of posthumously diagnosed MIRAGE syndrome (Myelodysplasia, Infection, Restriction of growth, Adrenal hypoplasia, Genital problems, and Enteropathy) in a girl with a new pathogenic SAMD9 variant (p.F437S), who was initially considered to have familial dysautonomia (FD)-like disease due to increased levels of catecholamine metabolites. Functional analyses of F437S-SAMD9 were performed, showing characteristics of disease-causing variants. This new SAMD9 variant (p.F437S) also causes MIRAGE syndrome.

Human Genome Variation (2021) 8:1-3; https://doi.org/10.1038/s41439-021-00158-6

Myelodysplasia, infection, restriction of growth, adrenal hypoplasia, genital problems, and enteropathy (MIRAGE) syndrome is a genetic disorder caused by gain-of-function SAMD9 mutations, which lead to a multisystemic growth restriction disorder ${ }^{1}$. Recently, several cases of patients with MIRAGE syndrome presenting with dysautonomia have been reported ${ }^{2-4}$. Familial dysautonomia (FD) is a rare genetic disease caused by a founder variant in the ELP1 gene ${ }^{5-9}$. FD involves impaired development of sensory and afferent autonomic nerves, which leads to widespread organ dysfunction and mortality ${ }^{8,9}$. Early signs and symptoms include hypotonia, feeding difficulties, growth restriction, a lack of tears, and frequent lung infections ${ }^{9}$. Most of these symptoms are also observed in patients with MIRAGE syndrome. In several patients with FD-like symptoms, no ELP1 mutation was identified $^{10,11}$. This study describes the case of a patient who presented with FD-like symptoms and myelodysplastic syndrome (MDS) with monosomy 7 and was posthumously diagnosed as having MIRAGE syndrome due to a rare SAMD9 variant.

The patient was born with severe asphyxia at 37.3 weeks of gestation (birth weight: $2.002 \mathrm{~g}$ [-2.1 SD]; birth length: $44 \mathrm{~cm}$ $[-1.6 \mathrm{SD}])$. The newborn had dysphagia, repeated apneic attacks, thrombocytopenia, and anemia. Additionally, dysautonomic conditions such as hyperhidrosis, paresthesia, and lacrimal deficiency were observed. External features included a flat upper lip and tongue mushroom papilla loss (Fig. 1A). The results of array comparative genomic hybridization were normal, and the patient was discharged at 4 months. At 8 months, the patient was diagnosed with MDS associated with monosomy 7. At 16 months, the patient experienced irritable contractions after the methacholine eye drop test, with increased levels of catecholamine metabolites (plasma norepinephrine: $1.79 \mathrm{ng} / \mathrm{mL}$ [range: $0.15-0.57$ ], urine homovanillic acid: $14.4 \mathrm{mg} / \mathrm{g}$ creatinine [range: $2.1-8.2$ ], urine vanillylmandelic acid: $2.93 \mathrm{mg} / \mathrm{g}$ creatinine [range: 2.4-8.3], ratio of homovanillic acid to vanillylmandelic acid: 2.93 [range $<1.5])^{12}$ and a negative histamine intradermal reaction (Fig. 1B). On the basis of these findings, we suspected FD. However, the analysis of the ELP1 gene revealed no mutations; therefore, the patient was considered to have an FD-like disease. Growth retardation continued (Fig. 1C). The patient experienced intermittent pneumonia and vomiting episodes with colonic dilation despite undergoing Nissen surgery and gastrostomy at 17 months of age. There was no adrenal insufficiency. Mental retardation was noted at 32 months. At 5.5 years, with progressing pancytopenia, bone marrow tests showed the progression of MDS to refractory anemia, with excess type 2 blasts (RAEB-2). Allogeneic bone marrow transplantation was performed at 5.75 years. Despite achieving complete remission, RAEB- 2 recurred at 6.33 years, leading to the patient's death.

The genetic profile of the patient remained unclear even after her death in 2013. MIRAGE syndrome was suspected when the condition was first reported in 2016. Genomic DNA and RNA were extracted from leukocytes, saliva, and fibroblasts obtained from the patient's right anterior chest skin. ELP1 expression was evaluated, and SAMD 9 was sequenced from genomic DNA isolated from fibroblasts, as previously described ${ }^{3,13}$. Genomic analysis revealed a heterozygous de novo missense SAMD9 mutation (NM_017654.4: c.1310T>C, p.F437S) (Fig. 2A). This mutation has not been reported in the gnomAD database, the 1000 Genomes database, or the Human Gene Mutation Database. The phenylalanine at position 437 (F437) is conserved across several species (Fig. 2B).

The effect of the F437S mutation on cell growth was evaluated in HEK293 cells expressing the native or mutated SAMD9 protein [Wild type (WT) and F437S, respectively] upon induction, which were established and analyzed to measure the growth rate, as previously described ${ }^{3}$. WT-SAMD9 expression induced mild

\footnotetext{
${ }^{1}$ Division of Pediatrics \& Perinatology, Tottori University Faculty of Medicine, Yonago, Japan. ${ }^{2}$ Department of Pediatrics, Shimane University Faculty of Medicine, Izumo, Japan. ${ }^{3}$ Department of Pediatrics, Tottori Prefectural Central Hospital, Tottori, Japan. ${ }^{4}$ Department of Molecular Endocrinology, National Research Institute for Child Health and Development, Tokyo, Japan. ${ }^{\otimes}$ email: yuki.kawashima@med.shimane-u.ac.jp
}

Received: 4 March 2021 Revised: 25 May 2021 Accepted: 18 June 2021 
A

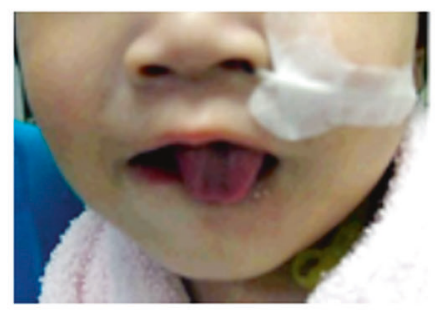

B

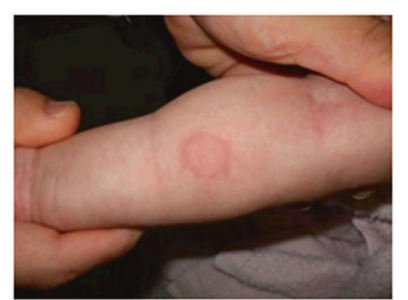

C

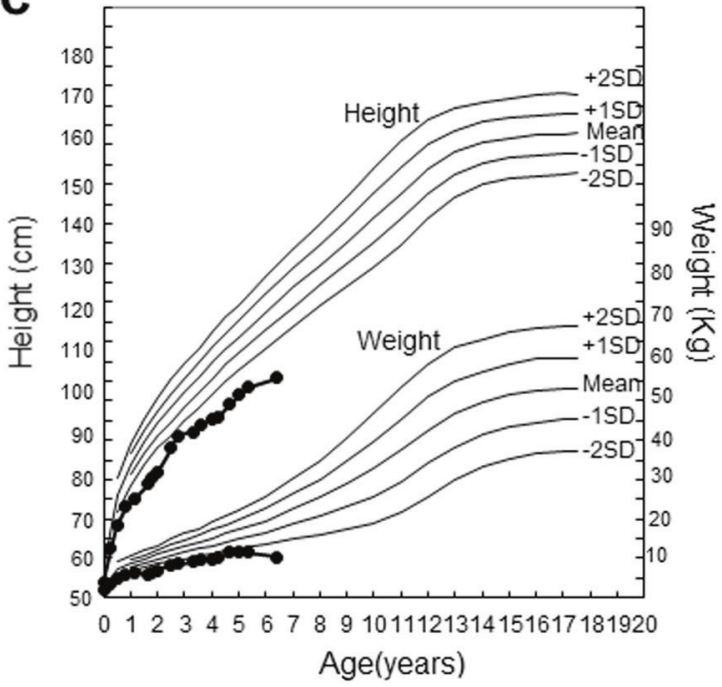

Fig. 1 Clinical findings. A The patient at 16 months of age, showing the flat upper lip and loss of tongue mushroom papillae. B Image 15 min after the histamine intradermal reaction test. Swelling and flare were not identified. C Patient cell growth curve.

A

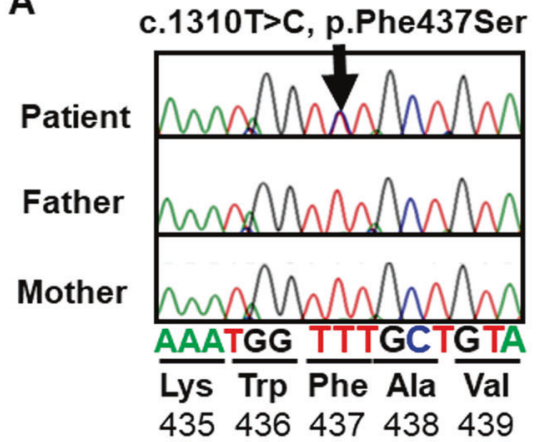

B

\begin{tabular}{rllllllll} 
Mutation & I & K & W & S & A & V & L \\
\hline Human SAMD9 & I & K & W & F & A & V & L \\
Rabbit Samd9 & I & K & W & F & A & V & L \\
Squirrel Samd9 & I & K & W & F & A & V & L \\
Horse Samd9 & I & K & W & F & A & V & L \\
Pig Samd9 & I & K & W & F & A & V & L \\
Cow Samd9 & I & K & W & F & A & V & L \\
Tasmanian devil Samd9 & I & K & W & F & A & V & L \\
Human SAMD9L & I & K & W & F & A & V & L \\
Rabbit Samd9l & I & K & W & F & A & V & L \\
Squirrel Samd9l & I & K & W & F & A & V & L \\
Horse Samd9l & I & K & W & F & A & V & L \\
Dog Samd9l & M & K & W & F & A & V & L
\end{tabular}

C Wild type

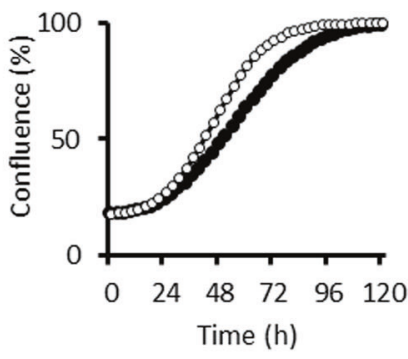

D

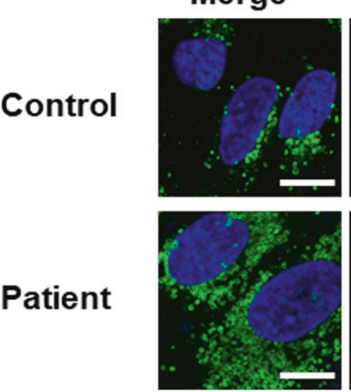

p.Phe437Ser

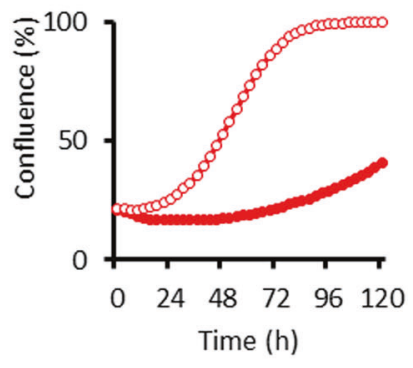

Nucleus

LAMP1
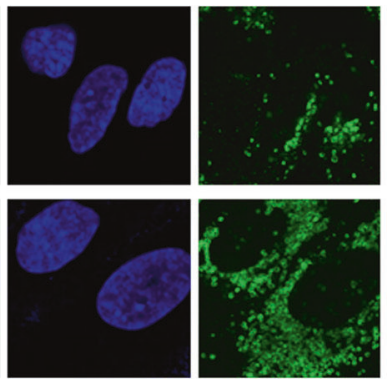

Fig. 2 Analysis of the SAMD9 variant in the patient. A Patient and parent polymerase chain reaction-amplified SAMD9 electropherograms; a heterozygous mutation was identified in the patient (arrow). B Alignment (Clustal software) showing the conserved F437 residue. C Growth curves of HEK293 cells transfected without (empty circles) or with (solid circles) wild-type (WT)-SAMD9 (left panel) and F437S-SAMD9 (right panel) plasmids. D Confocal image of patient-derived fibroblasts showing lysosomes and nuclei stained with anti-LAMP-1 antibody (green) and DAPI (blue), respectively.

growth suppression, as previously reported, whereas F437SSAMD9 inhibited cell growth (Fig. 2C). LAMP-1 visualization showed a remarkable increase in the lysosome number in the patient's fibroblasts (Fig. 2D), which is a characteristic of MIRAGE syndrome ${ }^{1,4}$. Thus, the patient was posthumously diagnosed with this syndrome.

Written informed consent for genetic analysis and the use of patient photos for publication was obtained from the patient's parents. This study was approved by the Ethical Review Board of the Tottori University School of Medicine, Japan (No. 19A066G), and conducted according to the principles of the Declaration of Helsinki.

Dysautonomia, including insensitivity and anhidrosis, has been reported in several MIRAGE syndrome cases $^{2-4}$. Conversely, dysautonomia at birth, feeding difficulties, poor growth, and frequent lung infections are observed only in FD and not in any other form of dysautonomia ${ }^{9}$. Interestingly, our patient also tested positive for laboratory test results common to FD, such as irritable 
contractions with the methacholine eye drop test, increased catecholamine metabolite levels, and a negative histamine intradermal reaction ${ }^{9,12}$. Further studies are warranted to determine whether ELP1 interacts with SAMD9. In conclusion, the new SAMD9 variant (p.F437S) also causes MIRAGE syndrome, and dysautonomia is considered a symptom that indicates the possibility of MIRAGE syndrome.

\section{HGV DATABASE}

The relevant data from this Data Report are hosted at the Human Genome Variation Database at https://doi.org/10.6084/m9. figshare.hgv.3042.

\section{REFERENCES}

1. Narumi, S. et al. SAMD9 mutations cause a novel multisystem disorder, MIRAGE syndrome, and are associated with loss of chromosome 7. Nat. Genet. 48, 792-797 (2016)

2. Jeffries, L. et al. A novel SAMD9 mutation causing MIRAGE syndrome: An expansion and review of phenotype, dysmorphology, and natural history. Am. J. Med. Genet. A 176, 415-420 (2018).

3. Shima, $\mathrm{H}$. et al. Two patients with MIRAGE syndrome lacking haematological features: role of somatic second-site reversion SAMD9 mutations. J. Med. Genet. 55, 81-85 (2018).

4. Ishiwa, S. et al. A girl with MIRAGE syndrome who developed steroid-resistant nephrotic syndrome: a case report. BMC Nephrol. 21, 340 (2020).

5. Riley, C. M. \& Day, R. L. Central autonomic dysfunction with defective lacrimation; report of five cases. Pediatrics 3, 468-478 (1949).

6. Maayan, C., Kaplan, E., Shachar, S., Peleg, O. \& Godfrey, S. Incidence of familial dysautonomia in Israel 1977-1981. Clin. Genet. 32, 106-108 (1987).

7. Anderson, SL. Coli, R. Daly, IW. Kichula, EA. Rork, MJ. Volpi, SA. et al. Familia dysautonomia is caused by mutations of the IKAP gene. Am. J. Hum. Genet $\mathbf{6 8}$, 753-758 (2001).

8. Cheishvili, D. Dietrich, P. Maayan, C. Even, A. Weil, M. Dragatsis, I. et al. IKAP deficiency in an FD mouse model and in oligodendrocyte precursor cells results in downregulation of genes involved in oligodendrocyte differentiation and myelin formation. PLoS One 9, e94612 (2014).

9. Axelrod, F. B. Familial dysautonomia. Muscle Nerve 29, 352-353 (2004).

10. Koy, A., Freynhagen, R., Mayatepek, E. \& Tibussek, D. Hereditary sensory and autonomic neuropathy with autonomic crises: a Turkish variant of familial dysautonomia? J. Child Neurol. 27, 191-196 (2012).

11. Gharagozlou, M., Zandieh, F., Tabatabaei, P. \& Zamani, G. Congenital sensory neuropathy as a differential diagnosis for phagocytic immunodeficiency. Iran. $J$. Allergy Asthma Immunol. 5, 35-37 (2006).
12. Geltzer, A. I., Gluck, L., Talner, N. S. \& Polesky, H. F. Familial dysautonomia; studies in a newborn infant. N. Engl. J. Med. 271, 436-440 (1964).

13. Kawashima, Y. Kanzaki, S. Yang, F. Kinoshita, T. Hanaki, K. Nagaishi, J. et al. Mutation at cleavage site of insulin-like growth factor receptor in a shortstaturechild born with intrauterine growth retardation. J. Clin. Endocrinol Metab. 90, 4679-4687 (2005).

\section{ACKNOWLEDGEMENTS}

We thank Dr. K. Adachi and Dr. E. Nanba for helping with ELP1 genetic analysis and Dr. J. Ueyama, Dr. H. Sano, Dr. N. Yoneda, Dr. N. Tamoto, Dr. Y. Mino, Dr. M. Fujimoto, and Dr. N. Miyahara for their contributions to this article. We thank the patient's parents for their continued cooperation even 6 years after the patient's death. This study was partly supported by grants from the National Center for Child Health and Development (2020B-3), JSPS (Kakenhi 19H03627), and Takeda Science Foundation.

\section{COMPETING INTERESTS}

The authors declare no competing interests.

\section{ADDITIONAL INFORMATION}

Correspondence and requests for materials should be addressed to Y.K-S.

Reprints and permission information is available at http://www.nature.com/ reprints

Publisher's note Springer Nature remains neutral with regard to jurisdictional claims in published maps and institutional affiliations.

(c) (i)

Open Access This article is licensed under a Creative Commons Attribution 4.0 International License, which permits use, sharing, adaptation, distribution and reproduction in any medium or format, as long as you give appropriate credit to the original author(s) and the source, provide a link to the Creative Commons license, and indicate if changes were made. The images or other third party material in this article are included in the article's Creative Commons license, unless indicated otherwise in a credit line to the material. If material is not included in the article's Creative Commons license and your intended use is not permitted by statutory regulation or exceeds the permitted use, you will need to obtain permission directly from the copyright holder. To view a copy of this license, visit http://creativecommons. org/licenses/by/4.0/.

(c) The Author(s) 2021 